\title{
The value of heterotopia space constructed by the hybridity of physical and digital interior design
}

\author{
J. Hidayat \\ Universitas Pelita Harapan, Tangerang, Indonesia \\ C. Dharmawan \\ Universitas Komputer Indonesia, Bandung, Indonesia
}

\begin{abstract}
Heterotopia is a theoretical concept referring to real space comprising characteristics such as ambiguous, temporary, contextual, personal, and illusive. It unveils the contradictive hidden meaning. The advance of digital technology in design brings forth the hybridity that delivers a spatial aesthetic experience in the form of an intervention space between the physical element with its constant trait and the digital space that is temporary; between a more objective construction of meaning and contextual or personal. The case study method was used in this study with objects from the Museum of the Bible, the Vuitton store, and the Miguel Chevalier Digital Art Installation. The result is that the value of heterotopia was used as a critique space and a representation of identity crisis precipitated by the encounter between physical and digital space. It in turn stipulates interior design to redefine the understanding of space. The meaning of space is a value which will always be present in a process of negotiating and reinterpreting.
\end{abstract}

Keywords: heterotopia, hybrid, digital, interior, illusive

\section{INTRODUCTION}

Digital art was first introduced by Harold Cohen (1928-2016), a British painter and academic who had been in the United States since 1968. In 1971, he published a drawing machine controlled by a computer. Cohen then developed a computer program for the drawing composition of lines, surfaces, and colors. The abstract drawing produced by this computer-controlled drawing machine was brought to the public at the Los Angeles County Museum of Air (1972), La Jolla Museum of Air in San Diego (1973), and the "Documenta" art exhibition in Kassel, Germany (1977). Cohen subsequently enhanced a more elaborate computer program which enabled the drawing machine to develop into a painting-fabricator machine that could produce figurative paintings such as floras, human paintings, as well as making simulations of colors decided upon by an artist. In the 1990s, this painting fabricator machine lost the competition to the printing machine which can produce a replica of a colored picture on large-sized paper, including canvas for paintings who also had unlimited opportunities for artists to create visual collages by combining images originating from photos, videos, and computer paintings, turning them into new works of art. The artificial intelligence, used to create paintings and the strategy of combining physical and digital images to generate a novelty, merged into the design world including interior design.

The first application of computer technology in interior design occurred in the making of design drawing, working drawing, and presentation drawing by using computer software such as AutoCAD since 1982, 3D Max Animation since 2005, Adobe Illustrator since 1986, and Adobe Photoshop since 1990, followed by design softwares for 2D and 3D drawings, such as SketchUp, TurboCad, Revit, Archicad, Infurnia, and Live Home 3D. Computer technology was also used on 3D printing machines to translate the 2D drawings into 3D models, in calculating the energy efficiency on 
the green designs and in the making of green construction (ConstructionSuite since 1999, Green Wizard, Autodesk Green Building Studio and Greengrade), and to create animated images, moving objects, simulations, and hyperreal spaces utilizing virtual reality. This study reviewed the combination of physical and digital elements in interior design to learn the values of hybrid space created when users experienced the mixture of static stable image and the constantly moving/changing image. The physical space has the temporary, ambiguous, dual coding (physical-digital) characteristics, which in turn generates the problem of representation referred to as Heteropia space by Michel Foucault in 1967.

\section{METHOD}

This study's question was how the value of Heterotopia space was created by the hybridity of physical and digital space elements. This research used the case study method with two bases as follows: (1) as a method that can be used to deepen a theory and its implementation in various cases and (2) to put theories into tests as well as enriching them to modify it and broadening the readers' horizon on contextual truth. The chosen cases were the Museum of the Bible in Washington, DC, the Luis Vuitton Store at Changi Airport, Singapore, and the Miguel Chevalier Digital Art Installation at Cathedral Notre-Dame, Rodez, France. They were chosen for the accessibility and capability in illustrating the theory to show Heterotopia space and the aesthetic experience created by it.

Based on Robert K. Yin's theory on Case Study Research (Yin 2014), the applied method of data collecting and analysis were (1) exploration of Heterotopia theory to generate the Heterotopia space characteristic analysis variable, (2) selection of cases and data collection through literature study and survey, (3) cases analysis, and (4) modification and implication of theory on the understanding and meaning of space.

\begin{tabular}{|c|c|c|c|}
\hline $\begin{array}{l}\quad \text { (1) } \\
\text { Exploring theory } \\
\text { of Heterotopia } \\
\text { Space- } \\
\text { generating } \\
\text { analysis } \\
\text { variables }\end{array}$ & $\begin{array}{l}\qquad(2 \mathrm{~A}) \\
\text { Selecting cases: Hybrid space of } \\
\text { physical-digital interiors: } \\
\text { Museum of the Bible } \\
\text { Louis Vuitton Store } \\
\text { Miguel Chevalier installation art } \\
\\
\text { (2B) } \\
\begin{array}{l}\text { Design data collection protocol: } \\
\text { literature study, survey }\end{array}\end{array}$ & $\begin{array}{l}\text { Write individual case analysis, } \\
\text { do comparison study between } \\
\text { cases on Heterotopia characters: } \\
\text { (1) Opposite-ambiguous of dual } \\
\text { coding } \\
\text { (2) Prompting perception } \\
\text { beyond physical space } \\
\text { (3) Temporer - transient } \\
\text { (4) Contextual - individual } \\
\text { (5) Illusive }\end{array}$ & $\begin{array}{l}(4) \\
\text { Write theory } \\
\text { modification, } \\
\text { implication as } \\
\text { conclusions: } \\
\text { The value of } \\
\text { Heterotopia space, } \\
\text { The changing of } \\
\text { aesthetic experience } \\
\text { that cause space } \\
\text { reinterpretation }\end{array}$ \\
\hline
\end{tabular}

Figure 1. Adaptation on the Yin Model of the case study research method.

\section{RESULT}

\subsection{Heterotopia space}

Heterotopia space is a real space with tangible physical elements, and a theoretical concept developed by Foucault (1967), with characteristics: (1) opposite and ambiguous character of double coding (physical and digital elements of space); (2) prompting perception beyond physical space; (3) temporary and transient; (4) contextual and individual; and (5) illusive (Hidayat 2005).

The first characteristic is the existence of opposing traits creating ambiguous meaning of the space. For that, the space meaning can be re-interpreted by different users. Within the hybridity between the physical and digital space, disparity emerges when the static physical element encounters the dynamic digital element having different concepts of form and significance.

The second characteristic is the appearance of spatial perception that goes beyond the boundaries of three-dimensional physical elements. The existence of tangible and measured Heterotopia is 
categorized as a real space, although it is beyond sensorial perception. It can occur when a space has a meaning related to the user's spirituality. When the appreciator experiences the space, he put(s) himself in the present as well as the past (nostalgia) on the same function or type of space.

The third characteristic is that Heterotopia space does not have a universal and consistent form, aside from having a different shape. Heterotopia also has various functions of space, depending on the context of time and space. In the traditional (in traditional) culture, a church has a sacred function as a place for worship. However, in the postmodern culture, it is possible to use a church as an art exhibition space, as exemplified by Chevalier's digital installation art. Within this context, two opposing characters present together: the sacred and the profane. The existence of a digital element enables the image in the space to continuously shift. It delivers various performances that are estranged from one another with different meanings that makes the visitors feel like being in a temporary transit area. Heterotopia professes a continuum characteristic toward the changing dimension of space and time. The metaphor uttered by Foucault is a sailing ship on the ocean, where a ship has no absolute space reference. The ship's space is an individual solitary space, but it is a part of a universal space with no boundaries (Mirzoeff 1998).

The fourth characteristic is that perception produced is contextual toward the user's cultural space. Different cultural backgrounds of users produce different engagement between users and the space. It happens when space has a digital element with changing images. In the time of advances of (in) information, communication, and modern transportation technology, people can swiftly move from one cultural space to another, and connect with people from various cultural spaces regardless (of) geographic and institutional barriers. The perception generated within a space may even become individual, unmapped, such as the ethnic culture.

The fifth characteristic is illusive. The function of Heterotopia space is creating an illusional space contesting the real. It puts boundaries on human life and generates human values that become the representation of artificial or superficial culture. Therefore, Heterotopia space has a critique function toward diverse ideology, social, and cultural problems.

\subsection{The heterotopia space characteristic of the Museum of the Bible}
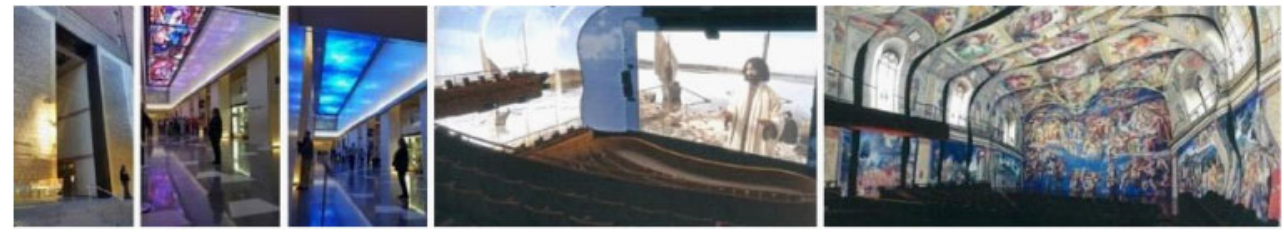

Figure 2. Entrance, lobby, and World Stage Theatre of the Museum of the Bible (entrance, lobby photos were taken on October 2018 survey, World Stage Theatre image is courtesy of the Museum of the Bible).

The Museum of the Bible in Washington, DC, has been open to the public since 2017. This museum's design uses a narrative approach in delivering visual language through storytelling. The implemented narrative design strategy is to create a multi-sensory perception by stimulating sensorials and movement using digital technology. The space chosen to represent physical and digital hybridity is the lobby, virtual reality area, and World Stage Theatre. The ceiling on the lobby corridor is a LED (Light Emitting Diode) digital screen panel with a projector connected to the computer, presenting different images. It enables visitors to experience spatial images that changes (change) as they walk through the corridor, creating a continuum of time-space accordance. It differs from the traditional design where a designer created one image concept for one space.

The dual coding within the space not only exists through the divergence between the static elements of floor, wall, and column to the temporary-dynamic images of the digital ceiling, but also happens due to differences in concept, content, and style of the image itself. The ceiling image is a limitless visual collage, starting from Middle Age classical, to Renaissance, to the Modern 
era, delivered by the computer screen on the ceiling that can be shifted anytime by the programmer following the content provided by the museum curator. This virtual reality (VR) area is a Heterotopia space because in this empty physical space, by using VR glasses, the visitors experience a VR tour of cultural spaces within the Bible. When experiencing the virtual space, it is as if visitors have traveled through the past time-space dimension, deriving a hyper-reality.

Hyper-reality is a spatial experience generated through simulation. Here, metaphysic representation, the vanishing of reality ideology, duplication of nostalgic, and fantasy world replaces the form-meaning (Piliang 1999, 2004). Digital technology was also applied in the World Stage Theatre, where walls and ceilings were covered by digital screens. This condition resulted in a continuously changing spatial image adjusting with the presentation currently displayed on the front screen, creating a $360^{\circ}$ virtual perception.

\subsection{Heterotopia space characteristic of a Louis Vuitton Store}
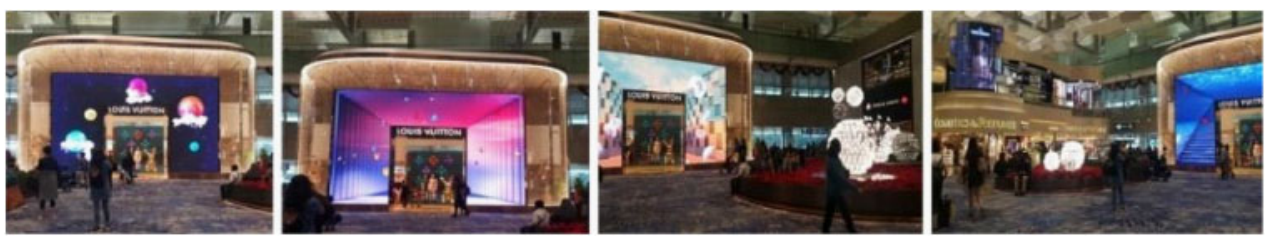

Figure 3. Louis Vuitton Store, Changi Airport, Singapore. (Photos were taken on December 2017 survey).

At Changi Airport, the Louis Vuitton Store has a storefront display different from the window displays found in traditional stores. Space hybridity occurs between the door as a physical element placed alongside a digital LED panel, creating a dynamic facade with its shifting images. The image displayed has no direct correlation with the store's product, rather representing the characteristic of a Louis Vuitton's product. The temporary and transient characteristics exist in this space, where visitors feel like taking a journey transiting from one fantasy realm to another.

Users experience individual illusions following the cultural context in constructing meaning. The hybrid space gave a less (gave less) of an intense effect since the digital element only of one (had one) visual panel. The design combination was still dominated by physical elements making the digital only as decorative for its monumental size, while the designer tried to create the illusion of fantasy-like space dimension to visitors.

\subsection{Heterotopia characteristic of the Chevalier installation art at The Notre-Dame Cathedral}
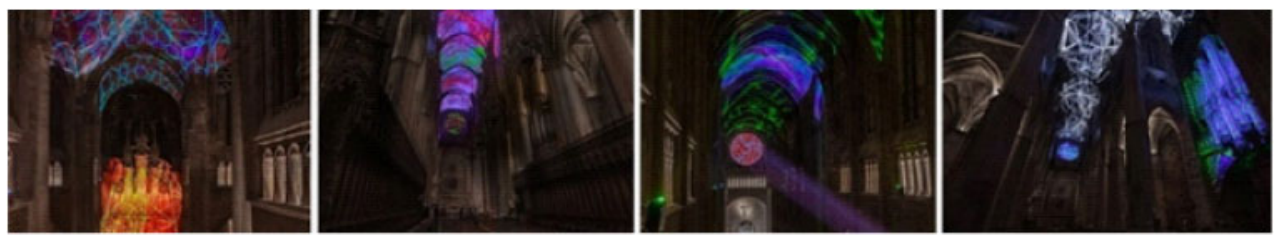

Figure 4. Digital Supernova Installation Art by Miguel Chevalier, Cathedral Notre-Dame, August 2019. (source: designboom.com, accessed July 2020).

Installation art by Miguel Chevalier at The Cathedral Notre-Dame in Rodez, France, in 2019 was presented during the evenings. The chosen time added a contrast to the characteristic and affected visitors' perception. This dual-coding happened in the church came from the physical material, digital characteristics, shape, color, and composition. 
The church has a gothic style with natural and monotonous colors. The digital art installation delivered a modern style with abstract forms and gleaming bright colors. The creation of the installation generated a novelty surfacing the form, due to high contrast expression came (coming) from the shape and color substance. This novelty also happened at the level of meaning.

In a church, light is a symbolic representation of God's presence. The darkroom symbolized the sinned human since sins are identical to miseries and despair. When a human repents, he feels God's presence and guidance within himself, like the light that comes into the darkroom. The light in a gothic church comes from the stained-glass composition.

In the Chevalier installation, the installation art's lines, surfaces, and colors produced luminescence that replaced the divine light. In this case, the light had no spiritual meaning, but a profane frenetic world of material. It is like congregations worship in a church while their minds are not on God but on their agendas, business, and worldly pleasures. Their body is in the church, but they have their mind on other places. This fractured-identity characteristic represented by the dual-coding existed within the art installation.

\section{DISCUSSION}

The digital element in a Heterotopia space takes part as an open variable. It delivers a continuously changing image causing the whole image of space unclear due to its dynamic. Basically, form and space's meanings have a singular and static relation, because the image and meaning narration are statics. The digital element makes the image of space temporary, as well as the perception it generates. Thus, space becomes transitional. When the floor, walls, and ceiling elements come in the form of a digital screen or panel, what is space?

Interior design's discipline understands space as a physical element consisting of tangible and measurable elements of floor, walls, and ceiling. This discipline also gives a comprehension of interiority seeing space in a more fluid understanding. It considers the imaginary space that does not always have complete physical components, but proffers the feeling of being sheltered, protected, and surrounded like being under a tree or walk in a narrow roofless corridor between buildings. What if the floor, wall, and ceiling elements can no longer be clearly defined when meaning has no longer become important compared to the shifting space image itself? The physical-digital hybrid space phenomenon brings back the space theory to the Lao Tzu philosophy that things always change and one remains unchanged is the way of becoming (Ven 1995).

Space is organic and existential because space is formed from the inside out, starting from imaginary personal space to hybrid physical and digital space. However, the interpretation of space is existential, depending on the context of being and time of humans who experience it. According to Heidegger, the spatial experience is phenomenological as Das sein is spatial and Das sein spatiality or lived spatiality or place is a representation of being in the world (Wollan 2003). When the meaning of space becomes unstable and unclear, it leads to a paradox. However, space becomes a medium to reflect or critic (criticize) when the meaning displayed on the surface differs from the one existing within the user's perception. When the museum users experience the historical space, not all of them treat it as a learning space, but as a background visual collage for self-existence in the social media, a space for spiritual pilgrimage, a space for dating, a pre-wedding photoshoot space, or a space for a fashion show. The same thing when a church is enabled as an art piece display space. The real space that is paradox like a utopian at the real-physical site, contested and inverted, is a Heterotopia space (Sajjad 2019).

\section{CONCLUSION}

The users obtain the ambiguous, temporary, transient, and illusive values of a Heterotopia space when they understand that those characteristics represent the actual reality of space as a unity of opposing characteristics. The being and not-being, static and dynamic, superficial and hidden 
meaning, explicit and implicit, those are the characteristics that represent the dynamic balance. This study confirms Cornelis van de Ven's articulation about Tao space theory (Ven 1995), that intervention between two opposing characteristics is the essential structure of temporary space aesthetic. The same goes for Deleuze and Guattari's viewpoint (Deleuze \& Guattari, 1994) that limitation is an illusion and determination is a negation unless if there is a relation between the determined and the one that is not; hybridity between physical and digital space.

\section{REFERENCES}

Deleuze, G. and Guattari, F. 1994. What is Philosophy? New York: Columbia University Press.

Hidayat, J. 2005. Bahasa Estetik Skizofrenia dalam Ruang Heterotopia: Studi Kasus Area Natah dalam Sintaks Tradisional Bali. Jurnal 2d3d. Tangerang, Banten: Fakultas Desain, Universitas Pelita Harapan.

Mirzoeff, N. 1998. Michel Foucault of other Spaces. New York: Routledge.

Piliang, Y.A. 1999. Hiper-realitas Kebudayaan. Yogyakarta: LKiS.

Piliang, Y.A. 2004. Posrealitas: Realitas Kebudayaan dalam Era Posmetafisika. Yogyakarta: Jalasutra.

Sajjad, N.u.A. 2019. Private Heterotopia and the Public Space: An Incongruity Explored through Orhan Pamuk's My Name is Red. Sage Open Journal 9(1). New York: Sage Publishing.

Ven, C.v.d. 1995. Ruang dalam Arsitektur (3rd Edition). Jakarta: Gramedia.

Wollan, G. 2003. Heidegger's Philosophy of Space and Place. Journal Norsk Geografisk Tidsskrift-Norwegian Journal of Geography 57(1): 31-39. Taylor \& Francis.

Yin, R.K. 2014. Case Study Research Design and Methods (5 Edition). Thousand Oaks, CA: Sage. 